\title{
REFLEXÕES SOBRE O TRABALHO COM A DIVERSIDADE LINGUÍSTICA \\ NA BASE NACIONAL COMUM \\ CURRICULAR NO COMPONENTE \\ LÍNGUA PORTUGUESA
}

\author{
BUSSE ,Sanimar ${ }^{1}$ \\ Evelin Stefanie Ferreira Andreolla ${ }^{2}$ \\ Lays Maynara Favero Fenilli ${ }^{3}$
}

\begin{abstract}
Resumo: Ao considerar que a língua não é algo estático, mas mutável e dinâmico, é importante que a escola ajude os alunos a compreenderem a realidade linguística com suas contradições e variedades, sua estrutura e seu funcionamento. Dessa forma, dada a relevância dos conceitos de variação e preconceito linguístico nesse âmbito, entende-se que os documentos norteadores do ensino precisam abordá-los e enfatizar a importância de seu estudo. Nosso objetivo nesse artigo é investigar a Base Nacional Comum Curricular, publicada em 2017, para o Ensino Fundamental, com o intuito de analisar se a abordagem feita pelo documento aos conceitos em estudo está em consonância com as pesquisas atuais da Sociolinguística. Partiremos dos estudos de Busse (2010; 2015), Bortoni-Ricardo (2005), Monteiro (2000), Oliveira (2005) Oliveira et al. (1989), Tarallo, (2005) entre outros. Como resultados, obtivemos a percepção de que os conceitos são abordados pelo documento, em alguns momentos, de forma coerente com os teóricos da área, porém, em outros, de forma incipiente e não aprofundada.
\end{abstract}

Palavras-chave: Variação linguística. Preconceito linguístico. Base Nacional Comum Curricular.

\section{REFLECTIONS ABOUT THE WORK WITH LINGUISTIC DIVERSITY IN THE BRAZILIAN NATIONAL COMMON CURRICULAR BASE ON THE PORTUGUESE LANGUAGE COMPONENT}

\begin{abstract}
Considering that the language is not static, but mutable and dynamic, it is important that the school help the students to understand the linguistic reality, with its contradictions, variations, structure and ways of functioning. So, due to the relevance of concepts as linguistic variation and prejudice in this field of study, the teaching guidance documents need to explain them and their importance. This article aims to investigate the Brazilian National Common Curricular Base, published in 2017, for the Elementary School, analyzing the approach of the document concerning the mentioned concepts and its theoretical relation with the current Sociolinguistics' researches. This study is grounded on the researches of Busse (2010; 2015), Bortoni-Ricardo (2005), Monteiro (2000), Oliveira (2005) Oliveira et al. (1989), Tarallo, (2005) among others. As results, we observed that the concepts are mentioned by the document, sometimes, in consonance with the theoretical studies, however, in other moments, they are explained in an incipient and not thorough way.
\end{abstract}

Key words: Linguistic variation. Linguistic prejudice. Brazilian National Common Curricular Base.

1 Doutorado em Estudos da Linguagem, pela Universidade Estadual de Londrina/UEL. Professor efetivo (dedicação integral) da Universidade Estadual do Oeste do Paraná/Unioeste. E-mail: sani_mar@yahoo.com.br.

2 Mestranda no Programa de Pós-Graduação Stricto Sensu em Letras/PPGL, na Universidade Estadual do Oeste do Paraná, UNIOESTE. E-mail: eve_stefanie@hotmail.com

3 Mestranda do Programa de Pós-Graduação em Letras - Nível de Mestrado com ênfase em Linguagem e Sociedade da UNIOESTE. E-mail: lays.fenilli@gmail.com 


\section{Considerações iniciais}

A língua em sua dinamicidade e complexidade expressa a representação da história dos homens, pois registra os processos de interação entre homem/meio e homem/homem (BUSSE, 2010). Podemos reconhecer nas múltiplas formas de representação os elementos que marcam as relações de força que se estabelecem entre os falantes. A relação entre língua e sociedade e a eleição de uma variedade como padrão não deve implicar o desconhecimento e desvalorização das demais variedades de uma língua no ensino. A escola tem, portanto, o objetivo de levar o aluno a conhecer a variedade padrão de uma língua, deveria reconhecer a diversidade linguística da comunidade de fala, introduzindo-a como conteúdo de ensino, para, assim, desenvolver a consciência sobre as diferentes variedades e sua adequação aos diferentes contextos de usos.

O princípio é a compreensão de que a língua não é algo estático e acabado, ao contrário, sua razão de ser e sua essência são a mutabilidade, a complexidade e a dinamicidade no interior das relações sociais. Segundo Busse (2015), a escola tem o importante papel de ajudar o aluno a compreender a realidade linguística com suas contradições e variedades, sua estrutura e seu funcionamento.

Reconhecer as relações que se estabelecem entre língua e sociedade e entre língua, sociedade e escola podem revelar diferentes visões sobre as formas de uso, prestígio e padrão. Conforme destaca Mollica (2009),

Torna-se importante saber que os indivíduos apresentam também perfis sociolinguísticos diferenciados em sociedades complexas e são obrigados a desempenhar inúmeros papéis num grande elenco de eventos de fala de que participam. É nessa medida que o trabalho do professor de línguas tem que considerar inúmeros contextos de fala, tirar partido das distintas experiências comunicativas dos alunos, de seus papéis sociais, de forma a desenvolver práticas variadas de letramento. (MOLLICA, 2009, p. 30)

Dada a importância de reconhecer a língua a partir da sua heterogeneidade, da sua construção histórica e social e, principalmente, a partir das suas modalidades de uso, buscamos analisar, neste trabalho, as orientações dos documentos curriculares normatizadores do ensino no Brasil, mais precisamente, a Base Nacional Comum Curricular (BNCC), lançada em 2017. O documento prevê uma padronização dos conteúdos de ensino para a educação básica brasileira no nível do Ensino Fundamental (EF), colocando-se como uma atualização dos Parâmetros Curriculares Nacionais, de 1998.

A partir disso, torna-se pertinente refletir sobre como determinados conceitos são abordados pelo documento e em que fundamentos teóricos se ancoram, considerando que a BNCC orientará a elaboração de todos os currículos pedagógicos municipais e estaduais brasileiros, dado seu caráter normativo.

Nossoobjetivo, nestetrabalho,éodeinvestigar como o referido documento aborda os conceitos "variação linguística" e "preconceito linguístico", com o intuito de analisar se tal abordagem vai ao encontro dos estudos desenvolvidos atualmente na área da Sociolinguística sobre o tema.

No que tange aos aspectos metodológicos, esta pesquisa se delineia como qualitativa e interpretativista (BORTONI-RICARDO, 2008), já que buscamos interpretar e refletir sobre o que se coloca na BNCC à luz dos pressupostos teóricos da Sociolinguística, de acordo com os estudos de Busse (2010; 2015), Bortoni-Ricardo (2005), Monteiro (2000), Oliveira (2005) Oliveira et al. (1989), Tarallo, (2005) entre outros. 


\section{Algumas considerações teóricas sobre variação e preconceito linguístico}

A concepção de língua como sistema socialmente determinado, heterogêneo, cuja variação estrutural está relacionada às alterações dos aspectos culturais, sociais e ideológicos do grupo opõe-se à concepção de língua como sistema homogêneo e autônomo que se impõe unitariamente a todos os falantes da comunidade linguística indistintamente (MONTEIRO, 2000).

Conforme destaca Busse (2010), as línguas submetem-se aos diferentes fatores da vida concreta dos homens, da história de cada sociedade em seus menores e singulares detalhes. A pesquisa sobre os diferentes aspectos de representação da vida, em suas diversas configurações trata das relações entre a sociedade e as línguas como um todo, dedicandose aos fatores essenciais à própria natureza da linguagem humana.

Bortoni-Ricardo (2008) destaca que tal postura teórica e tal forma de compreender a língua têm implicações pedagógicas já que, segundo ela,

$[\ldots]$ a linguística recomenda que a norma
culta seja ensinada nas escolas, mas que,
paralelamente, se preservem os saberes
sociolinguísticos e os valores culturais que
o aluno já tenha aprendido antes, no seu
ambiente social. Resguarda-se, assim, o direito
que o educando possui à preservação de sua
identidade cultural específica, seja ela rural
ou urbana, popular ou elitista (BORTONI-
RICARDO, 2005, p. 26).

Nos estudos da variação e mudança linguística, mais precisamente na Sociolinguística, encontramos a possibilidade de "descrever e analisar as modalidades de uso de línguas e dialetos dentro de uma dada cultura, os eventos de fala, as regras para seleção adequada dos falantes", conforme destaca Monteiro (2000, p. 28).

A respeito da oposição padrão/não-padrão, formas conservadoras/formas inovadoras, formas estigmatizadas/formas de prestígio, Tarallo (2005, p. 11-12) chama atenção para o fato de que esta relação de concorrência nem sempre é verificada, pois podem surgir situações conflitantes de acordo com "a dimensão que as atitudes sociolingüísticas podem alcançar". Situações em que uma forma nãopadrão assume papel mais forte na comunidade só podem ser explicadas mediante o "encaixamento sociolinguístico da variável na comunidade de fala", e este depende da atitude que os falantes, condicionados por questões culturais e sociais, assumem.

Ao ingressar na escola, o falante conhece basicamente todos os recursos linguísticos, nos níveis fonético-fonológico, morfossintático e semântico-lexical, bem como a sua função, e é capaz de utilizá-las nas diversas situações comunicativas. Para Mollica (2009), diante desse conhecimento inato e adquirido,

\begin{abstract}
[...] o professor deve lançar mão dos saberes linguísticos inatos dos educandos, tirando partido da oralidade, para então estimular nos alunos o desenvolvimento de sua potencialidade como falante. $\mathrm{O}$ trabalho com a leitura e a escrita partirá de conhecimentos do próprio falante no esforço de, ao apropriar-se do código ortográfico, atingir níveis de maior complexidade nos processos de ler e escrever. (MOLLICA, 2009, p. 27).
\end{abstract}

Reconhecer as variantes do seu grupo de fala como formas legítimas da sua identidade linguística pode auxiliar o aluno a compreender-se como ator social nos diferentes ambientes de comunicação, segundo Busse (2015). Ao transitar por diferentes ambientes e compreender seu papel como agente comunicativo, os conhecimentos sobre a língua levarão os alunos a relacionarem cada variedade a situações específicas de interação. Entendemos que se trata de criar uma consciência sociolinguística que se pauta no conhecimento das variedades linguísticas e seu papel comunicativo.

Segundo Bortoni-Ricardo (2005, p. 14), “o comportamento linguístico é um indicador 
claro da estratificação social. Os grupos sociais são diferenciados pelo uso da língua." Além, da distribuição de bens materiais e culturais, podemos afirmar que a língua traz no seu conjunto de variedades, os elementos da história e da cultura dos grupos, uma hierarquia social que remete à formação das comunidades e da convivência entre os diferentes grupos.

Considerando o que pressupõem os currículos do ensino básico e o conhecimento das características presentes na fala dos alunos e suas respectivas localidades, o professor possui subsídios para orientar sua prática pedagógica de modo a expandir a competência comunicativa do aluno, bem como o uso de uma linguagem com maior prestígio, pois a relação entre variantes da LP, a fala e a escrita, "precisa ser estudada e compreendida para que possamos auxiliar os alunos a construírem seu conhecimento sobre a escrita, refutando, reformulando e consolidando suas hipóteses” (BUSSE, 2015, p. 28-29).

A discussão sobre a variação linguística na escola propicia o desenvolvimento da consciência fonológica do aluno, considerando o contexto multicultural brasileiro existente o e os múltiplos gêneros em que os textos ocorrem (inclusive na oralidade), contemplando as situações comunicativas que exigem maior ou menor monitoramento no uso da língua. Conforme destaca Busse (2015),

Em comunidades multilíngues ou multidialetais a consciência fonológica é fator preliminar para a compreensão da relação fala e escrita, considerando que a percepção dos sons da língua auxilia o aluno a compreender o seu funcionamento, na modalidade oral e escrita. Destacamos, aqui, a necessidade de observar que a oralidade não compreende apenas a manifestação mais espontânea e informal da língua. Ela também comporta situações de interação em que se deve manter o controle da variedade padrão, como palestras, entrevistas, conferências e outras. (BUSSE, 2015, p. 31).

Dessa forma, o uso padrão da linguagem foi associado à classe de maior prestígio social, mas há um fator determinante na composição dessa classe: os falantes são oriundos de diferentes contextos formativos, que interferem significativamente na organização desse uso e sobre como a língua passará pelas transformações. No entanto, como assevera Bortoni-Ricardo (2005), "No Brasil, tem-se um grande contingente da população, cuja economia linguística é predominantemente oral e que, portanto, não tem acesso à força padronizadora da língua escrita" (BORTONI-RICARDO, 2015, p. 24), constituindo, assim, um imensurável acervo linguístico do país.

Esse acervo precisa ser uma das preocupações em sala de aula, já que

\begin{abstract}
As variedades linguísticas faladas pelos alunos indicam o domínio da língua da comunidade e, principalmente, sua compreensão sobre a função da linguagem nos processos de interação dos quais participam. Esse conhecimento deve ser ponto de partida para a aprendizagem da variedade padrão, considerando a sua função social, que é inerente a determinados eventos comunicativos, em que a língua deve ser mais monitorada. (BUSSE, 2015, p. 29 -30).
\end{abstract}

Nesse viés, ressalta-se a importância de que o aluno perceba por quais motivos existem diferentes dialetos, enfatizando os diversos aspectos da variação, já que as construções se modificam de acordo com a situação de produção da fala (gênero discursivo, suporte do texto, interlocutor, posição social do falante, momento histórico, etc.), assegurando que a escolha da variedade nas diversas esferas da sociedade é consequência de preceitos sociais, dos quais os alunos precisam estar conscientes. 


\section{A BNCC: contextualização documento}

A Base Nacional Comum Curricular teve sua versão definitiva publicada em 2017. Foi desenvolvida por uma equipe de profissionais ligados ao Ministério da Educação (MEC), ao Conselho Nacional de Secretários de Educação (Consed), à União Nacional dos Dirigentes Municipais de Educação (Undime), às universidades brasileiras e, na revisão, contou com alguns professores da Educação Básica.

Segundo o que consta em sua introdução, a BNCC

[...] é um documento de caráter normativo que define o conjunto orgânico e progressivo de aprendizagens essenciais que todos os alunos devem desenvolver ao longo das etapas e modalidades da Educação Básica, de modo a que tenham assegurados seus direitos de aprendizagem e desenvolvimento, em conformidade com o que preceitua o Plano Nacional de Educação (PNE). (BRASIL, 2017, p.05, grifo dos autores).

Assim, assegura-se sua normatividade e seu alinhamento com o PNE, enfocando a educação como um direito dos cidadãos. Partindo disso, o documento afirma estar "orientado pelos princípios éticos, políticos e estéticos que visam à formação humana integral e à construção de uma sociedade justa, democrática e inclusiva, como fundamentado nas Diretrizes Curriculares Nacionais da Educação Básica”. (BRASIL, 2017, p.05).

Ainda na introdução, afirma-se que a BNCC é uma estratégia desenvolvida para que a educação básica brasileira seja comum, tanto no âmbito dos conteúdos, quanto das avaliações nacionais e também na formação de professores. Para tanto, o documento deve servir de "Referência nacional para a formulação dos currículos dos sistemas e das redes escolares dos Estados, do Distrito Federal e dos Municípios e das propostas pedagógicas das instituições escolares" (BRASIL, 2017, p.06).
O documento se coloca como ponto de partida para a elaboração de todos os documentos organizadores do ensino em nível municipal, estadual, regional e nacional, que devem, no entanto, adequar as proposições para "as necessidades, as possibilidades e os interesses dos estudantes, assim como suas identidades linguísticas, étnicas e culturais" (BRASIL, 2017, p.06), buscando considerar, também, a diversidade e a equidade educacional nos contextos específicos.

No que tange à sua organização, a BNCC foi construída tendo em vista competências gerais e competências específicas para cada disciplina ${ }^{4}$. Essas competências são a categoria ao redor da qual vão se desdobrar os conteúdos e habilidades dentro das áreas e disciplinas. No documento, afirma-se que as competências compreendem a

[...] indicação clara do que os alunos devem 'saber' (considerando a constituição de conhecimentos, habilidades, atitudes e valores) e, sobretudo, do que devem 'saber fazer' (considerando a mobilização desses conhecimentos, habilidades, atitudes e valores para resolver demandas complexas da vida cotidiana, do pleno exercício da cidadania e do mundo do trabalho). (BRASIL, 2017, p. 11, grifos dos autores).

Assentado nesse princípio, parao componente de LP, o documento afirma que busca atualizar os Parâmetros Curriculares Nacionais, publicados em 1998, com relação às pesquisas recentes da área e às transformações ocorridas nas práticas de linguagem, dando enfoque às tecnologias digitais de informação e comunicação (TDIC).

Para o componente de LP, assume-se a "perspectiva enunciativo-discursiva de linguagem" (BRASIL, 2017, p. 63) considerando a linguagem como "uma forma de ação interindividual orientada para uma finalidade específica; um processo de interlocução que se realiza nas práticas sociais existentes numa sociedade, nos distintos

4 Termo equivalente, no documento, a "componente curricular". 
momentos de sua história" (BRASIL, 1998, p. 20 apud BRASIL, 2017, p. 63). Nessa perspectiva, considera-se o texto como unidade de trabalho, o que confere a ele centralidade na definição dos conteúdos, habilidades e objetivos.

Segundo o documento, ao componente de LP, cabe

[...] proporcionar aos estudantes experiências que contribuam para a ampliação dos letramentos, de forma a possibilitar a participação significativa e crítica nas diversas práticas sociais permeadas/constituídas pela oralidade, pela escrita e por outras linguagens. (BRASIL, 2017, p. 63).

A partir disso, o componente é abordado por meio de quatro eixos: Eixo da Leitura, Eixo da Produção de Textos, Eixo da Oralidade e Eixo da Análise Linguística/Semiótica. Subdivide suas considerações em duas seções: uma para os anos iniciais e outra para os anos finais do EF.

Análise das considerações/indicações da BNCC sobre variação e preconceito linguístico no componente LP

A seção destinada ao componente curricular Língua Portuguesa é iniciada com diretrizes gerais sobre esse componente, com observações a respeito do papel dele na formação dos alunos e sobre questões que, na visão do documento, merecem ser enfocadas por ele, das quais, variação e preconceito linguístico fazem parte.

Dentro dessas observações, o documento reconhece a diversidade linguística no país e destaca a importância da abordagem desse aspecto:

Ainda em relação à diversidade cultural, cabe dizer que se estima que mais de 250 línguas são faladas no país - indígenas, de imigração, de sinais, crioulas e afro-brasileiras, além do português e de suas variedades [...] Assim, é relevante no espaço escolar conhecer e valorizar as realidades nacionais e internacionais da diversidade linguística e analisar diferentes situações e atitudes humanas implicadas nos usos linguísticos, como o preconceito linguístico. (BRASIL, 2017, p. 66).
Percebe-se, nessa primeira menção, que o documento reconhece a diversidade linguística e dialetal no país e o preconceito linguístico como conceitos reais e dignos de atenção no ensino de LP, resultado das atitudes linguísticas em relação ao convívio das variedades. No que tange ao preconceito, o documento o reconhece como uma atitude humana que é implicada pelos usos linguísticos e que merece ser tema de análise.

Ao colocar como objetivo o verbo conhecer, a BNCC avança na compreensão da necessidade de estudar as diferentes formas de uso da língua, principalmente, no que se refere ao convívio entre as diferentes línguas e os diferentes falares, como resultados da diversidade cultural.

Avaliamos, porém, que a diversidade linguística precisa ser tomada, também, como realidade que se origina nas diferentes situações de comunicação, condicionada por variáveis, como faixa etária, escolaridade e sexo.

Depois das diretrizes gerais, o documento passa a discutir cada eixo de ensino e suas dimensões. No Eixo da Leitura, não encontramos nenhuma menção aos conceitos aqui estudados.

Entendemos que, ao estudar os diferentes gêneros discursivos e seus suportes e suas esferas de circulação o aluno entrará em contato com registros de ordem diversa, os quais evidenciam variantes linguísticas de acordo com a sua dimensão mais próxima da oralidade e menos monitorada. A atividade de leitura poderá auxiliar o aluno a compreender que os diferentes registros orientam sentidos em alguns textos, como, por exemplo, buscar a adesão do interlocutor. Tratase, portanto, de observar a língua e suas variedades e compreender seu uso a partir dos objetivos interlocutivos.

No Eixo da produção de textos, o documento aborda a variação linguística no quadro em que apresenta as dimensões desse eixo, 
mais especificamente na dimensão denominada "Estratégias de Produção":

Desenvolver estratégias de planejamento, revisão, edição, reescrita/redesign e avaliação de textos, considerando-se sua adequação aos contextos em que foram produzidos, ao modo (escrito ou oral; imagem estática ou em movimento etc.), à variedade linguística e/ou semioses apropriadas a esse contexto, os enunciadores envolvidos, o gênero, o suporte, a esfera/ campo de circulação, adequação à norma-padrão etc. (BRASIL, 2017, p. 74).

No Eixo da Oralidade, as variedades linguísticas são mencionadas no quadro das dimensões, precisamente na dimensão "Relação entre fala e escrita". Nesse quadro documento aponta a necessidade de "Refletir sobre as variedades linguísticas, adequando sua produção a esse contexto" (BRASIL, 2017, p. 74).

Nota-se que as variedades linguísticas são trazidas à luz como um dos aspectos da língua para o qual o aluno precisa se atentar na produção de textos, para que sejam usadas adequadamente em relação ao contexto do texto a ser escrito/falado. Não há orientação sobre os elementos que pauta as dimensões oral e escrita da língua. Apesar de a escola pautar avaliação e acompanhamento dos alunos, prioritariamente, sobre o escrito, a oralidade deve assumir o papel que lhe cabe na comunicação. Assim, deve-se atentar às formas de expressão oral que partem do menos ao mais monitorado. Ao professor cabe o papel de mediador do letramento, ao criar situações de uso da língua em diferentes contextos, que vão do espontâneo, como a conversa informal, ao monitorado, entrevista, seminário, entre outros.

Estabelecem-se, assim, situações de reflexão sobre a língua.

No Eixo da Análise Linguística/Semiótica a variação linguística é abordada tanto nas considerações gerais quanto no quadro das dimensões. Primeiramente, o documento enfoca que é na análise do estilo linguístico que as variedades da língua precisam ser levadas em conta. Em seguida, aborda a variação de forma mais enfática, apontando que:

Cabem também reflexões sobre os fenômenos
da mudança linguística e da variação linguística,
inerentes a qualquer sistema linguístico, e que
podem ser observados em quaisquer níveis de
análise. Em especial, as variedades linguísticas
devem ser objeto de reflexão e o valor social
atribuído às variedades de prestígio e às
variedades estigmatizadas, que está relacionado
a preconceitos sociais, deve ser tematizado.
(BRASIL, 2017, p. 74).

No que toca à relação entre as variedades e a apreciação/valoração social que lhes é conferida na sociedade, Bortoni-Ricardo (2005), assevera que

\begin{abstract}
Os professores e, por meio deles, os alunos, têm que estar bem conscientes de que existem duas ou mais maneiras de dizer a mesma coisa. E mais, que essas formas alternativas servem a propósitos comunicativos distintos e são recebidas de maneira diferenciada pela sociedade. Algumas conferem prestígio ao falante, aumentando-lhe a credibilidade e o poder de persuasão; outras contribuem para formar-lhe uma imagem negativa, diminuindolhe as oportunidades. (BORTONI-RICARDO, 2005, p. 15).
\end{abstract}

Assim, pelo fato de alguns falantes terem sua fala estigmatizada e sua atuação em sociedade prejudicada por isso, o ensino das variantes de prestígio figura como um direito que precisa ser garantido a esses falantes, pois "O caminho para uma democracia é a distribuição justa de bens culturais, entre os quais a língua é o mais importante" (BORTONI-RICARDO, 2005, p. 15).

Apesar de o documento corroborar o que dizem os autores da área, percebe-se que, ao destacar a variação e seu caráter natural e legítimo dentro do estudo da língua, utiliza a expressão "sistema linguístico" para se referir às línguas. Essa expressão remete a uma concepção de língua/ linguagem denominada por Geraldi (1984) de "concepção de linguagem como instrumento de comunicação". Dentro dessa perspectiva, a língua 
é vista como um sistema pronto e fechado, como algo fixo e estável, o que acaba por anular o caráter mutável e variável que os estudos da Sociolinguística conferiram a ela.

Nota-se, então, que a variação é abordada, porém, os termos utilizados denotam uma concepção de língua que não condiz com uma "perspectiva enunciativo-discursiva de linguagem" (BRASIL, 2017, p. 63), como afirmado no início da seção de LP do documento, tampouco com a ideia de que as línguas mudam e variam naturalmente, como destacado por Busse (2015), ao tratar da noção de erro: "Olhar para o fenômeno da variação na língua a partir da noção de erro, lapso ou desvio significa ignorar que as línguas mudam no tempo, no espaço geográfico e socialmente. É desconsiderar que a mudança é fator de manutenção das línguas vivas" (BUSSE, 2015, p. 29).

O preconceito linguístico é justificado, muitas vezes, por um entendimento que considera o erro um entrave para a compreensão nos níveis semânticos, pragmáticos, morfológicos e fonéticos e por não atender ao uso padrão das formas faladas. Entretanto, frequentemente, esse preconceito ocorre não por causar falta de compreensão entre os falantes, mas por um desconforto de alguns falantes ao se depararem com o uso de algumas formas que são estigmatizadas em relação à variedade prestigiada. No entanto, a variação linguística, como comentado acima, é um fenômeno não estanque e que faz com que as línguas transformem-se de acordo com os aspectos históricos, regionais, sociais e estilísticos e faz com que as línguas se mantenham em uso. Assim, muitas vezes, uma língua muda para atender às novas formas de os falantes se expressarem e construírem suas identidades à medida que as formas de letramento se transformam.

Além disso, o prestígio conferido à normapadrão é de caráter social e histórico, ou seja, conforme Bortoni-Ricardo (2005), "Não se reconhece nela qualquer valor inerente ou intrínseco, mas, sim, atributos que se desenvolveram ao longo de um processo sócio-histórico de natureza institucional" (BORTONI-RICARDO, 2005, p. 25).

Após abordar esses aspectos, o documento traz a variação dentro do quadro das dimensões norteadoras da Análise Linguística/Semiótica, criando agora, uma dimensão específica ("Variação linguística"), para o assunto, que compreende:

Conhecer algumas das variedades linguísticas
do português do Brasil e suas diferenças
fonológicas, prosódicas, lexicais e sintáticas,
avaliando seus efeitos semânticos. Discutir, no
fenômeno da variaçãa linguística, variedades
prestigiadas e estigmatizadas e o preconceito
linguístico que as cerca, questionando suas
bases de maneira crítica (BRASIL, 2017, p. 79).

Nessa dimensão, percebe-se um tratamento mais detalhado das possíveis imbricações que a variação linguística pode trazer ao uso da língua, como as diferenças fonológicas, que são muito importantes na abordagem das diversas variedades (e na eliminação dos preconceitos linguísticos), visto serem, entre algumas variedades, as diferenças mais de mais fácil percepção e alvo de estigmatização.

Se observarmos, por exemplo, a construção "Me dá" em início de frase (que, conforme a gramática normativa - que baliza a modalidade escrita - estaria "errada", sendo o "certo" a construção "Dá me", já que os pronomes oblíquos, segundo essa gramática, devem vir em início de frase, antes do verbo), podemos perceber que ela não tem uma avaliação tão negativa quanto as diferenças fonológicas de algumas regiões do Brasil, como o alofone R (retroflexo) em "porta", por exemplo, que resulta na estigmatização de seus falantes.

Após abordar o Eixo da Análise Linguística/ Semiótica e apresentar os campos de atuação das práticas de linguagem, o documento apresenta, como síntese da seção, um quadro de competências 
para a disciplina de LP no EF. Dentre elas, a competência de número quatro é endereçada à variação: "Compreender o fenômeno da variação linguística, demonstrando atitude respeitosa diante de variedades linguísticas e rejeitando preconceitos linguísticos” (BRASIL, 2017, p. 83).

Assim, a variação linguística é considerada, pelo viés das competências, como algo que os alunos "devem 'saber" e que deve ser articulada, em forma de conhecimento, às habilidades, atitudes e valores que permearão as ações e permitirão o engajamento dos alunos na sociedade, balizando, dessa forma, o que eles vão "saber fazer", que, nesse caso se refere à utilização da língua.

\section{Anos Iniciais do Ensino Fundamental}

As considerações destinadas aos anos iniciais do EF abordam de forma ampla o processo de alfabetização que acontece nesse período escolar. Dessa forma, para falar sobre a aprendizagem do alfabeto pelo aluno, o documento aponta o fato de que a LP tem muitas variedades e que a escrita, ou seja, nesse caso, as letras, de certa forma, uniformizam o que o aluno vai compreender por LP: “[...] estamos tratando de uma língua com suas variedades de fala regionais, sociais, com seus alofones, e não de fonemas neutralizados e despidos de sua vida na língua falada local. De certa maneira, é o alfabeto que neutraliza essas variações na escrita" (BRASIL, 2017, p. 86).

Ainda no que tange ao processo de alfabetização, o documento aborda a importância de o aluno saber sobre as diversas variedades da LP para a compreensão da relação fone-fonemagrafema:

Na construção desses conhecimentos, há três relações que são muito importantes: a) as relações entre a variedade de língua oral falada e a língua escrita (perspectiva sociolinguística); b) os tipos de relações fono-ortográficas do português do Brasil; e c) a estrutura da sílaba do português do Brasil (perspectiva fonológica). Mencionamos a primeira relação ao dizer que a criança está relacionando com as letras não propriamente os fonemas (entidades abstratas da língua), mas fones e alofones de sua variedade linguística (entidades concretas da fala) (BRASIL, 2017, p. 87).

Observa-se, então, a preocupação do documento em ressaltar a variação como parte do processo de alfabetização, e que precisa ter a atenção do professor, já que a variedade do aluno, na maioria dos casos, acaba por influenciar o processo de aquisição da escrita, pois nessa fase, como aponta Oliveira (2005),"o aprendiz associa o sistema de escrita alfabética, num primeiro momento, ao conhecimento que ele tem do sistema fonológico de sua língua (no caso, o português)" (OLIVEIRA, 2005, p. 8) na variedade que a utiliza. Segundo Oliveira et al. (1989), essa relação (oralidade-escrita) só vai ficar mais clara para o aluno, "quando descobrir a postura adequada: a escrita é um código de representação, não de transcrição, da fala" (OLIVEIRA et al., 1989, p. 24). Porém, até que o aluno chegue nesse estágio de conhecimento das modalidades da língua, passa por um estágio em que o reconhecimento de sua variedade de fala, pode deixar claro para o professor, as hipóteses que esse aluno está construindo durante a aprendizagem da escrita.

A valorização das variedades linguísticas é destacada pelo documento a partir do seu reconhecimento em diferentes textos e respectivos gêneros. Assim, o documento, corrobora Bagno (2014), quando o autor afirma que

É preciso ampliar o repertório e a competência
linguística dos aprendizes, levá-los a se apoderar
da escrita e dos muitos gêneros discursivos
associados a ela, sem contudo desprezar suas
variedades linguísticas de origem, valorizando-
as, ao contrário, como elementos formadores
de sua identidade individual e social e como
patrimônio cultural do país. (BAGNO, 2014,
s/p).

Percebemos que o documento, nesse trecho, vai ao encontro do que afirma Bagno (2014) 
destacando o estudo das variedades, o respeito por todas elas e a rejeição ao preconceito. Entretanto, mesmo que a variação seja enfocada nas diretrizes gerais para os anos inicias, ela não é mencionada nas tabelas como conteúdo para os $1^{\text {os }}$ e $2^{\text {os }}$ anos.

Conforme Busse (2015),

Não há uma metodologia mais eficiente para a compreensão do funcionamento da escrita, que não seja aquela em que o aluno se coloque como autor do seu projeto de dizer, ou seja, que ele tenha o que dizer, para quem dizer, com um objetivo. Se a sala de aula funcionar como um laboratório em que ele manipule a língua para diferentes ações, a escrita será compreendida como representação da linguagem em ambientes mais ou menos monitorados, a partir de seu status social (BUSSE, 2015, p. 40, grifo do autor).

As diretrizes gerais para os anos iniciais, o documento se organiza em tabelas que trazem como categorias: Práticas de Linguagem, Objetos de Conhecimento e Habilidades. As primeiras tabelas trazem essas categorias abrangendo de $1^{\circ}$ ao $5^{\circ}$ ano e, em seguida, apresentam-se tabelas com conteúdos para $1^{\text {os }}$ e $2^{\text {os }}$ anos e para $3^{\text {os }}$ aos $5^{\text {os }}$ anos.

Nas tabelas de cunho geral para os anos iniciais e nas de $1^{\mathrm{os}}$ e $2^{\mathrm{os}}$ anos, não encontramos menção ao estudo da variação linguística. Ainda que nesse período da escolarização a atenção seja voltada especialmente para a alfabetização, não se encontram, por exemplo, na Prática de Linguagem (no eixo) "Oralidade", indicadores que pontuassem o estudo de aspectos relacionados à variação ou à relação fala-escrita (como apontado nas diretrizes gerais).

Nesse eixo, na tabela de $1^{\text {os }}$ aos $5^{\text {os }}$ anos, encontram-se habilidades como: "Expressar-se em situações de intercâmbio oral com clareza, preocupando-se em ser compreendido pelo interlocutor e usando a palavra com tom de vOz audível, boa articulação e ritmo adequado" (BRASIL, 2017, p. 91). Assim, delega-se ao eixo escrita, a aquisição do alfabeto por meio do trabalho com textos escritos, e ao eixo oralidade aspectos como "clareza", "tom de voz" e "ritmo", o que faz com que as variedades linguísticas não sejam parte dos conteúdos desses eixos.

Nas tabelas de $3^{\text {os }}$ aos $5^{\text {os }}$ anos, encontramos a variação linguística como um Objeto de Conhecimento dentro da Prática de Linguagem "Oralidade". Para tal Objeto de Conhecimento, o documento nomeia como Habilidade: Ouvir gravações, canções, textos falados
em diferentes variedades linguísticas,
identificando características regionais, urbanas
e rurais da fala e respeitando as diversas
variedades linguísticas como características do
uso da língua por diferentes grupos regionais
ou diferentes culturas locais, rejeitando
preconceitos linguísticos. (BRASIL, 2017, p.
108).

Observamos que o documento busca rejeitar o preconceito linguístico a partir do reconhecimento das variedades linguísticas e seus traços regionais. Destacamos, porém, que o conteúdo precisa ser trabalhado de forma a levar o aluno a observar que na sua comunidade de fala há diferentes grupos, que suas manifestações linguísticas se sobrepõem, muitas vezes, devido a fatores econômicos e culturas. Partir da sua própria comunidade leva o aluno a situar-se e a compreender que as variedades linguísticas ultrapassam espaços físicos e limites sociais, pois, para cada grupo, representam sua história e sua cultura.

O reconhecimento das variedades linguísticas, inclusive a padrão, deve ser pautado na pesquisa e na reflexão sobre a identidade dos grupos e a coexistência dos diferentes falares na comunidade, principalmente, quando representam diferentes lugares sociais, como, por exemplo, o lugar do grupo folclórico, da igreja, da escola, do grupo de amigos, da associação de bairros, de algumas profissões etc. Assim, o aluno refletirá sobre o preconceito linguístico e encontrará elementos na história e na própria língua para reconhecer as 
atitudes dos falantes e os estereótipos construídos sobre determinados traços da língua, para superar a discriminação social baseada nas variedades linguísticas.

\section{Anos Finais do Ensino Fundamental}

No que diz respeito aos anos finais do EF, as diretrizes gerais não abordam o tema variação linguística de forma explícita. As tabelas de conteúdos dividem-se em $6^{\text {os }}$ aos $9^{\text {os }}$ anos, $6^{\text {os }}$ e $7^{\text {os }}$ anos e $8^{\text {os }}$ e $9^{\text {os }}$ anos.

A variação linguística é apresentada como Objeto de Conhecimento na tabela geral de Habilidades para os $6^{\text {os }}$ aos $9^{\text {os }}$ anos. Nessa tabela, a variação está dentro da Prática de Linguagem "Análise Linguística/Semiótica" e compreende as Habilidades: "Reconhecer as variedades da língua falada, o conceito de norma-padrão e o de preconceito linguístico" e "Fazer uso consciente e reflexivo de regras e normas da norma-padrão em situações de fala e escrita nas quais ela deve ser usada" (BRASIL, 2017, p. 157).

Nota-se que as habilidades propostas dentro desse Objeto de Conhecimento abordam a variação e o preconceito sempre em relação à normapadrão. Pensando as variedades linguísticas como opostas à variedade considerada padrão. Não fica explícito no documento como deveria ser abordada essa relação. Utilizam-se os termos "reconhecer" e "uso reflexivo", por exemplo, mas eles não garantem a abordagem desses conteúdos por meio de uma "pedagogia culturalmente sensível", como proposto por Bortoni-Ricardo (2005). Para tal autora, pelo uso dessa pedagogia, "em lugar da dicotomia entre português culto e português ruim, institui-se na escola uma dicotomia entre letramento e oralidade" (BORTONI-RICARDO, 2005, p. 132).

Em seguida, o documento traz a variação linguística como Objeto de Conhecimento na tabela destinada aos $8^{\text {os }}$ e $9^{\text {os }}$ anos, dentro da prática de Linguagem "Análise Linguística/Semiótica", apontando a seguinte Habilidade: "Identificar estrangeirismos, caracterizando-os segundo a conservação, ou não, de sua forma gráfica de origem, avaliando a pertinência, ou não, de seu uso" (BRASIL, 2017, p. 186).

Percebe-se, então, que em relação aos anos finais do EF, o documento aponta a variação linguística como conteúdo geral, destacando as variedades e o preconceito linguístico como conceitos para serem trabalhados em sala sem detalhar metodologicamente os encaminhamentos para o trabalho com os fenômenos, sua função social e suas representações sociais. E, de forma pontual, aponta-se para o estudo dos estrangeirismos e sua pertinência na LP.

\section{Considerações finais}

A partir das reflexões desenvolvidas, podemos perceber que os conceitos de variação e preconceito linguístico são abordados nos estudos da variação e mudança linguística a partir da compreensão de que se trata de um fenômeno intrínseco às línguas naturais, pois a mudança linguística ocorre em relação às necessidades dos falantes de usar a língua nos mais diversos contextos comunicativos.

Por meio do conhecimento e estudo do caráter natural da variação, é possível considerar que o preconceito linguístico ocorre por razões sócio-históricas que fizeram com que a variedade padrão seja considerada como tal e que recebesse maior prestígio social em relação às demais.

No que tange ao tratamento desses conceitos pela BNCC, observamos que o documento os aborda nas diretrizes gerais apenas uma vez. O mesmo acontece com o eixo da Produção Textual e o da Oralidade. No eixo de leitura não foi encontrada nenhuma menção à variação linguística. 
Já no eixo da Análise Linguística/Semiótica, o documento aborda a variação e o preconceito linguístico de forma mais enfática, entretanto, em alguns momentos, os termos utilizados denotam uma concepção de linguagem não condizente com a concepção adotada pelo documento ou pelos estudos sociolinguísticos.

Ao observar as indicações para os anos iniciais do EF, percebe-se que o documento aborda a relação da alfabetização com o a variedade linguística dos alunos, porém, nas tabelas de conteúdo, inclui o conceito apenas uma vez de forma não aprofundada. No que tange aos anos finais do EF encontramos a variação linguística como Objeto de Conhecimento duas vezes, sendo que em uma delas é relacionada ao conceito de preconceito linguístico e em outra se destina a reflexões sobre o uso de estrangeirismos na LP.

Diante disso, concluímos que os conceitos são abordados pelo documento, em alguns momentos, de forma coerente com os teóricos da área, porém, em outros, de forma incipiente e não aprofundada. Além disso, pela extensão do documento, observase que os conceitos são pouco explorados, dada sua importância no contexto do ensino de LP.

\section{REFERENCIAS}

BAGNO, Marcos. Variação linguística. In: FRADE, Isabel Cristina Alves da Silva; COSTA VAL, Maria da Graça; BREGUNCI, Maria das Graças de Castro (orgs). Glossário Ceale: termos de alfabetização, leitura e escrita para educadores. Belo Horizonte: UFMG/Faculdade de Educação, 2014. Disponível em: <http:// twixar.me/96Tn> Acesso em: $10 \mathrm{dez} 2018$.

BORTONI-RICARDO, Stella Maris. Educação em língua materna. A sociolinguística na sala de aula. São Paulo: Parábola, 2004.

Nós cheguemu na escola, e agora? Sociolinguística \& educação. São Paulo:
Parábola, 2005.

BRASI. Ministério da Educação. Base Nacional Comum Curricular. Brasília: MEC, 2017.

BUSSE, Sanimar. Um Estudo Geossociolinguístico da Fala do Oeste do Paraná. 2010. Tese (Doutorado em Estudos da Linguagem) - Universidade Estadual de Londrina/UEL, Londrina, 2010.

Variação Linguística e Ensino: Os desafios do ensino de Língua Portuguesa. In: COSTA-HÜBES, Terezinha da Conceição (Org.). Práticas sociais da linguagem: reflexões sobre oralidade, leitura e escrita no ensino. Campinas, SP: Mercado das Letras, 2015.

GERALDI, João Wanderley. O texto na sala de aula. Cascavel: Assoeste, 1984.

MOLLICA, Maria Cecília. A formação em linguagem. In. MOLLICA, Maria Cecília (Org.). Linguagem: para formação em Letras, Educação e Fonoaudiologia. São Paulo: Contexto, 2009.

MONTEIRO, José Lemos. Para compreender Labov. Petrópolis, RJ: Vozes, 2000.

OLIVEIRA, Marco Antônio et al. Da forma sonora da fala à forma gráfica de escrita: uma análise linguística de alfabetização. Cadernos de estudos linguísticos, Campinas, v.16, $\mathrm{n}^{\circ} 16$, p.5-30, jan./jun. 1989. Disponível em:<https:// bit.ly/2Cf6i9z> Acesso em: $11 \mathrm{dez} 18$

Conhecimento lingüístico e apropriação do sistema de escrita: caderno do formador. Belo Horizonte: Ceale/FaE/UFMG, 2005. Disponível em: <https://bit.ly/2zYiOsu> Acesso em: 11 dez. 18.

TARALLO, Fernando. A pesquisa sociolinguística. São Paulo: Ática, 2005.

Submissão: fevereiro de 2020 .

Aceite: março de 2020. 